\title{
Alignment of retention time obtained from multicapillary column gas chromatography used for VOC analysis with ion mobility spectrometry
}

\author{
Thorsten Perl • Bertram Bödeker • Melanie Jünger • \\ Jürgen Nolte • Wolfgang Vautz
}

Received: 1 February 2010 /Revised: 21 April 2010 /Accepted: 27 April 2010 /Published online: 30 May 2010

(C) The Author(s) 2010. This article is published with open access at Springerlink.com

\begin{abstract}
Multicapillary column (MCC) ion mobility spectrometers (IMS) are increasingly in demand for medical diagnosis, biological applications and process control. In a MCC-IMS, volatile compounds are differentiated by specific retention time and ion mobility when rapid preseparation techniques are applied, e.g. for the analysis of complex and humid samples. Therefore, high accuracy in the determination of both parameters is required for reliable identification of the signals. The retention time in the MCC is the subject of the present investigation because, for such columns, small deviations in temperature and flow velocity may cause significant changes in retention time. Therefore, a universal correction procedure would be a helpful tool to increase the accuracy of the data obtained from a gaschromatographic preseparation. Although the effect of the carrier gas flow velocity and temperature on retention time is not linear, it could be demonstrated that a linear alignment can compensate for the changes in retention time due to common minor deviations of both the carrier
\end{abstract}

\section{T. Perl $(\square)$}

Department of Anaesthesiology,

Emergency and Intensive Care Medicine, University of Göttingen,

37073 Göttingen, Germany

e-mail: tperl@gwdg.de

B. Bödeker $\cdot$ M. Jünger $\cdot$ J. Nolte $\cdot$ W. Vautz

Metabolomics Department,

ISAS-Institute for Analytical Sciences,

44139 Dortmund, Germany

Present Address:

B. Bödeker

B\&S Analytik,

44227 Dortmund, Germany gas flow velocity and the column temperature around the MCC-IMS standard operation conditions. Therefore, an effective linear alignment procedure for the correction of those deviations has been developed from the analyses of defined gas mixtures under various experimental conditions. This procedure was then applied to data sets generated from real breath analyses obtained in clinical studies using different instruments at different measuring sites for validation. The variation in the retention time of known signals, especially for compounds with higher retention times, was significantly improved. The alignment of the retention time - an indispensable procedure to achieve a more precise identification of analytesusing the proposed method reduces the random error caused by small accidental deviations in column temperature and flow velocity significantly.

Keywords Gas sensors · Chemical sensors . Gas chromatography $\cdot$ Bioanalytical methods

\section{Introduction}

Ion mobility spectrometry was originally developed for the detection of chemical warfare agents, explosives and illegal drugs [1-4]. In combination with a multicapillary column (MCC), the method is suitable to identify and quantify analytes even in complex and humid gas samples. Ion mobility spectrometers (IMS) provide high sensitivity (detection limits down to the picogram per litre and parts per trillion by volume range) combined with relatively low technical expenditure and high-speed data acquisition. 
MCC-IMS are increasingly in demand for medical diagnosis, therapy and medication control via breath analyses [57], as well as additional biological applications [8-10] and process control [11-13]. Using MCC-IMS directly for clinical diagnosis allows results to be obtained in minutes, and it provides additional information that can be used to determine the therapeutic strategy. Thus, these studies [5-7] could lead to the analysis, via ion mobility spectrometry, of volatile metabolites in human breath using ion mobility spectrometry as a way to obtain early diagnoses of selected diseases.

For this purpose, an analyte database including the characteristic retention time and ion mobility for the identification of the detected signals by comparison has to be provided. This database is not yet available commercially, as, for example, the NIST database for the evaluation of gas chromatography/mass spectrometry spectra. Recently, at ISAS (Leibnitz Institute for Analytical Sciences, Dortmund, Germany) such a database was assembled from measurements of reference analytes, in particular those found to be relevant for medical applications, using a calibration gas generator (HovaCal 3834SP-VOC, Inspire Analytical Systems, Frankfurt am Main, Germany). This database is growing continuously. Compounds are differentiated by specific retention time and ion mobility, and quantification is possible by signal intensity if a calibration has been previously carried out [14]. The categorical requirement for sound application and exploitation of such a database is high accuracy of both retention time and ion mobility for the identification of unknown signals [15]. An applicable attempt for the normalisation of the ion mobility using the reactant ion peak position in a known matrix gas as an internal standard has been implemented with good results and is presently in use at ISAS [16].

For alignment of ion mobility, the application of different internal standards is discussed frequently in the literature $[17,18]$. However, the demands on an internal standard are that it is a nontoxic and inexpensive substance with appropriate retention time and ion mobility. The compound has to delineate an area in the MCC-IMS that allows it to be differentiated from potential analytes. This criterion makes the choice of the suitable standard challenging and encourages a search for alternatives.

In combination with an IMS, the MCC is operated with relatively high flow rates because this leads directly to an increase in the sensitivity in ion mobility spectrometry. Furthermore, a constant operating temperature is chosen to enable breath analysis in an appropriate time period (less than $10 \mathrm{~min}$ ). The retention time in the MCC is the subject of the present study, as small accidental deviations in temperature (in the range $1-5^{\circ} \mathrm{C}$ ) and flow velocity (in the range $1-5 \mathrm{~mL} / \mathrm{min}$ ), as well as slightly changing characteristics and the length of the column, can cause significant deviations (in the range 5-25\%) in the retention time. These changes cause an uncertain or even false identification of compounds by retention time, especially when the ion mobility values are similar. Deviations of the retention time may be caused by variations of the backpressure of the column, the temperature and the carrier gas flow rate. The reason for such variations might be due to the tolerances of the equipment used for the control of those parameters as well as to their failure or to faulty operation. Furthermore, owing to the sampling procedure, a drop of the backpressure when the volume of the sample loop is injected into the column may cause further deviations, especially for low flow rates and for low retention times.

The impacts of systematic changes over a broad range of MCC temperature and of the carrier gas flow rate on the resulting retention time separately for representative analytes were investigated in this study. The interrelation between flow rate, temperature and retention time can be described by regression models with non-linear results in both cases. However, during real operation, in general, it is not possible to decide whether carrier gas flow rate or temperature deviations or a combination of both is responsible. Therefore, it is not possible to know which correlation would be appropriate for their correction. Indeed, the expected deviations in flow rate and temperature can be estimated to be less than $5{ }^{\circ} \mathrm{C}$ and $5 \mathrm{~mL} / \mathrm{min}$, respectively, when significant changes in the experimental conditions can be excluded. Therefore, the intention of the study was to validate the application of a simple linear regression as an alignment procedure.

A linear alignment procedure for the expected range of deviations was developed for the correction of small random deviations in flow velocity and MCC temperatures and was validated using a gas mixture of analytes with a range of retention times. Finally, the procedure was applied to real data sets obtained from breath analyses using different instruments at different measuring sites to prove the suitability of this approach.

\section{Experimental}

Multicapillary column ion mobility spectrometry

For the present study, a custom-designed MCC-IMS with a ${ }^{63} \mathrm{Ni} \beta$-ionisation source with synthetic air as the drift gas and operated at ambient pressure was used as described in detail elsewhere [1, 16, 19]. Therefore, only a brief description will be given here. The working principle of the MCC-IMS (see Fig. 1) is based on preseparation by a MCC, ionisation of the analytes and determination of the drift time in a weak electric field in synthetic air as the drift gas. The IMS is operated at ambient pressure and temperature. 
Fig. 1 An ion mobility spectrometer (IMS) with optional preseparation as designed at ISAS for breath analysis [16]

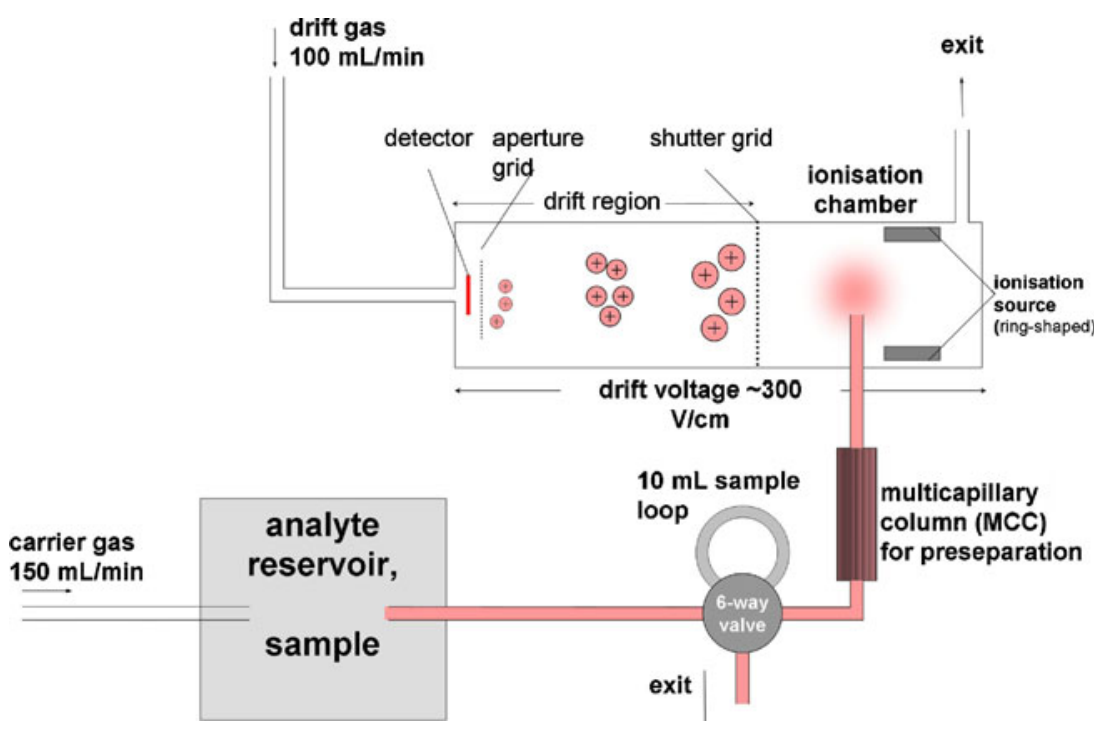

A 20-cm non-polar multicapillary gas-chromatographic column (OV-5, Multichrom, Novosibirsk, Russia) was used for preseparation. The column contains approximately 1,000 capillaries, each with an inner diameter of $40 \mu \mathrm{m}$ and a film thickness of $0.2 \mu \mathrm{m}$. The column allowed a gas flow rate of up to $250 \mathrm{~mL} / \mathrm{min}$ and was operated exclusively in an isothermal mode. Standard operation conditions are a carrier gas flow rate of $150 \mathrm{~mL} / \mathrm{min}$ and a temperature of $40{ }^{\circ} \mathrm{C}$.

The measurement is started by introduction of the volume of the sample loop $(10 \mathrm{~mL})$ via a six-way valve into the MCC. After separation, the analytes are injected directly into the ionisation chamber. An electrical shutter grid is opened for $300 \mu$ s every $100 \mathrm{~ms}$, thus allowing an ion cloud to enter the drift region (length $12 \mathrm{~cm}$ ) accelerated by an electrical field of approximately $300 \mathrm{~V} / \mathrm{cm}$. During their drift towards the detector, the ions are separated by collisions with the drift gas molecules into ion swarms of the same characteristics (cross-section and charge). From the measured drift time of these ion swarms, the reduced ion mobility is calculated (drift velocity normalised to the electric field, temperature and pressure of the drift gas, see Eq. 1) [2]:

$K_{0}=\frac{L}{E t_{D}} \frac{p}{p_{0}} \frac{T_{0}}{T}$

where $K_{\mathrm{o}}$ is the reduced ion mobility $\left(\mathrm{cm}^{2} / \mathrm{Vs}\right), L$ is the length of the drift region $(\mathrm{cm}), E$ is the electric field strength $(\mathrm{V} / \mathrm{cm}), t_{\mathrm{D}}$ is the drift time $(\mathrm{s}), p$ is the pressure of the drift gas $(\mathrm{hPa}), p_{\mathrm{o}}$ is the normal pressure $\left(p_{\mathrm{o}}=\right.$ 1,013.2 $\mathrm{hPa}), T$ is the temperature of the drift gas $(\mathrm{K})$ and $T_{\mathrm{o}}$ is the normal temperature $\left(T_{\mathrm{o}}=273.2 \mathrm{~K}\right)$

Additionally, the general set-up of the MCC-IMS is shown in Fig. 1.
Permeation tubes

For gas-mixture experiments, the analyte concentrations were provided with the help of permeation tubes. In all cases, about $300 \mathrm{mg}$ of analytes was placed into a $1-\mathrm{mL}$ glass vial, which was shielded by a permeable membrane. For both mixtures used - one with eight and one with 15 different analytes (Table 1, all obtained from SigmaAldrich, Munich, Germany) - all the glass vials with the particular analytes were placed together into a $150-\mathrm{mL}$ bottle, which was kept at constant temperature $\left(30^{\circ} \mathrm{C}\right)$ and constant gas flow rate $(200 \mathrm{~mL} / \mathrm{min}$ synthetic air) [20]. The substances were selected as compounds commonly occurring in breath analysis and being eluted over a broad range of retention times.

By choice of appropriate membranes, the concentrations of the particular compounds were adjusted to achieve a sufficient signal when $10 \mathrm{~mL}$ (sample loop volume) of gas sample (lower parts per billion down to parts per trillion range) is introduced into the MCC-IMS. The retention times obtained and summarised in Table 1 are the results from multiple measurements with six different MCC-IMS of the same design but from different production series. During the present study no efforts were made regarding quantification.

2-Nonanone was used as the alignment substance for the experiments with reference mixtures. The reduced ion mobility $K_{0}$ of $1.455( \pm 0.001) \mathrm{cm}^{2} / \mathrm{V} \mathrm{s}$ and the retention time of $51.3( \pm 4.3) \mathrm{s}$ were determined from 108 individual measurements. The mean retention time was designated as the reference retention time for all subsequent experiments with the gas mixtures. For the breath analyses, benzothiazole, with a reduced ion mobility $K_{0}$ of $1.75( \pm 0.004) \mathrm{cm}^{2} /$ $\mathrm{V}$ s, was chosen as the alignment substance. It was available as a continuous contaminant in the synthetic air 
Table 1 Compounds used for the reference gas mixtures. The retention time $\left(t_{\mathrm{R}}\right)$ was determined as the mean from 108 measurements

2-Nonanone was used as the alignment substance.

${ }^{\text {a }}$ Compounds used in flow variation experiments and for comparison of different instruments

${ }^{\mathrm{b}}$ Compounds used in multicapillary column (MCC) temperature variation experiments

\begin{tabular}{|c|c|c|c|c|}
\hline Compound & CAS no. & $\begin{array}{l}\text { Monomer reduced } \\
\text { ion mobility }\left(\mathrm{cm}^{2} / \mathrm{Vs}\right)\end{array}$ & $\begin{array}{l}\text { Dimer reduced ion } \\
\text { mobility }\left(\mathrm{cm}^{2} / \mathrm{Vs}\right)\end{array}$ & $t_{\mathrm{R}}(\mathrm{s})$ \\
\hline 2-Hexanone ${ }^{\mathrm{a}, \mathrm{b}}$ & $591-78-6$ & $1.718 \pm 0.001$ & $1.564 \pm 0.002$ & 7.3 \\
\hline 2-Heptanone ${ }^{\mathrm{a}, \mathrm{b}}$ & $110-43-0$ & $1.622 \pm 0.001$ & $1.261 \pm 0.002$ & 12.9 \\
\hline 2-Octanol ${ }^{\mathrm{a}, \mathrm{b}}$ & $4128-31-8$ & $1.432 \pm 0.001$ & $1.128 \pm 0.002$ & 27.2 \\
\hline D-Limonene $e^{\mathrm{a}, \mathrm{b}}$ & $5989-27-5$ & $1.688 \pm 0.001$ & $1.554 \pm 0.001$ & 29.5 \\
\hline 1-Octanol ${ }^{\mathrm{a}, \mathrm{b}}$ & $111-87-5$ & $1.393 \pm 0.001$ & & 47.7 \\
\hline 2-Nonanone $\mathrm{e}^{\mathrm{a}, \mathrm{b}}$ & $821-55-6$ & $1.455 \pm 0.001$ & $1.009 \pm 0.003$ & 51.3 \\
\hline Isopulegol $^{\mathrm{b}}$ & $89-72-2$ & $1.467 \pm 0.001$ & $1.087 \pm 0.003$ & 73.4 \\
\hline Naphtalene ${ }^{\mathrm{b}}$ & $91-20-3$ & $1.845 \pm 0.001$ & & 85.7 \\
\hline$(-)-$ Menthol $^{\mathrm{b}}$ & $2216-51-5$ & $1.663 \pm 0.002$ & $1.405 \pm 0.002$ & 93.7 \\
\hline Decanal $^{\mathrm{b}}$ & $112-31-2$ & $1.290 \pm 0.004$ & $1.008 \pm 0.003$ & 130.5 \\
\hline Carvone $^{\mathrm{b}}$ & $6485-40-1$ & $1.542 \pm 0.002$ & $1.129 \pm 0.002$ & 163.2 \\
\hline 1-Decanol ${ }^{\mathrm{a}, \mathrm{b}}$ & $112-30-1$ & $1.278 \pm 0.001$ & & 271.8 \\
\hline Thymol $^{\mathrm{b}}$ & $89-83-8$ & $1.590 \pm 0.002$ & & 306.0 \\
\hline 2-Undecanol ${ }^{\mathrm{a}, \mathrm{b}}$ & $1653-30-1$ & $1.255 \pm 0.001$ & $0.971 \pm 0.001$ & 338.3 \\
\hline Diisopropylphenol $^{\mathrm{b}}$ & $2078-54-8$ & $1.489 \pm 0.002$ & & 462.42 \\
\hline
\end{tabular}

used. By experiments with 2-nonanone as a reference, the retention time of benzothiazole was determined to be 118.3 $( \pm 8.5) \mathrm{s}$ as the mean from 108 measurements as well.

\section{Results and discussion}

Influence of carrier gas flow rate

To determine the influence of the carrier gas flow rate on retention time, the flow rate was varied from 30 to $210 \mathrm{~mL} /$ min (steps of $30 \mathrm{~mL} / \mathrm{min}$ and additionally $100 \mathrm{~mL} / \mathrm{min}$ ) in the permeation tube set-up with eight substances (Table 1, compounds indexed by superscript $a$ ). In Fig. 2, the variation of the retention time of these eight compounds with different carrier gas flow rate is presented. The slope of the retention time can be described by a correlation (Eq. 2) with good agreement (Fig. 2, $R^{2}=0.9931$, dashed line as an example for 1-decanol) for all analytes:

$t_{R}(x)=a x^{b}$

where $t_{\mathrm{R}}$ is the retention time, $a$ is the linear correlation to the retention time at $150 \mathrm{~mL} / \mathrm{min}\left(a=63 \mathrm{t}_{\mathrm{R}(150 \mathrm{~mL} / \mathrm{min})}\right), x$ is the carrier gas flow rate and $b$ is a constant $(-0.83)$.

The linear factor and the exponent are similar for all the analytes and therefore Eq. 2 can be rewritten as

$t_{R}(x)=63 t_{R(150 \mathrm{~mL} / \min )} x^{-0.83}$.

This equation is valid for the entire range of carrier gas flow rates suitable for the MCC used. As mentioned before, the flow rate used for MCC-IMS breath analysis is $150 \mathrm{~mL} /$
Fig. 2 Variation of the retention time of the selected analytes with different carrier gas flow rates. An example potential regression for 1-decanol is indicated by the dotted line $\left(R^{2}=0.9931\right)$

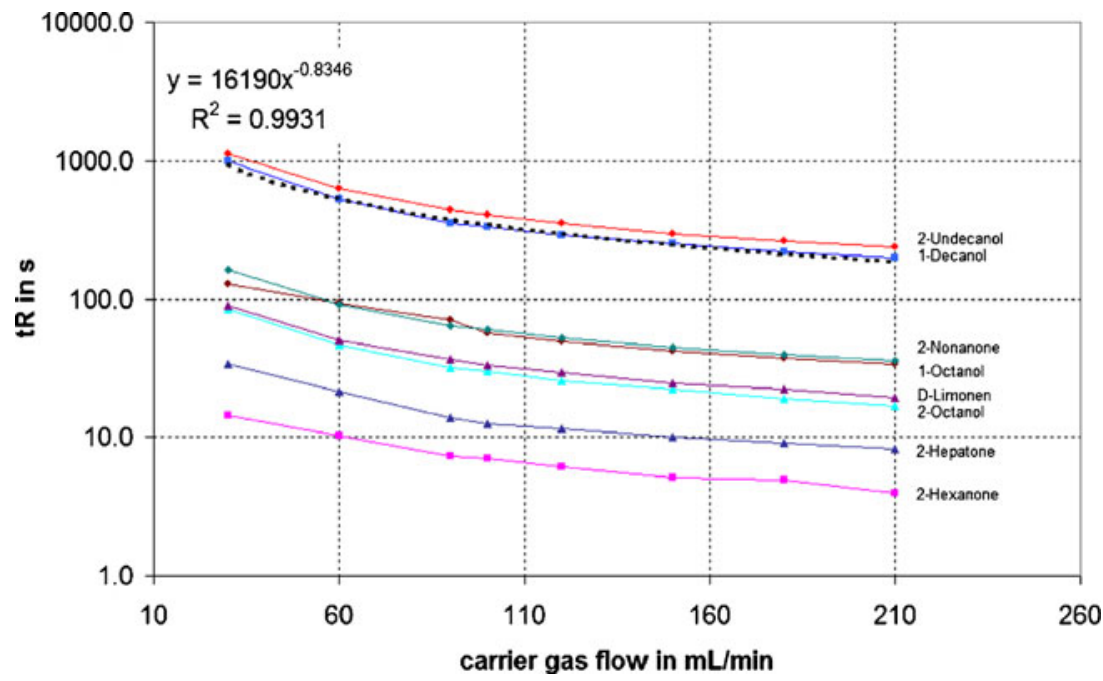


Fig. 3 Variation of the retention times of 2-undecanol and decanal as examples of the 15 compounds investigated with different multicapillary column (MCC) temperatures. Potential fittings are indicated by solid lines

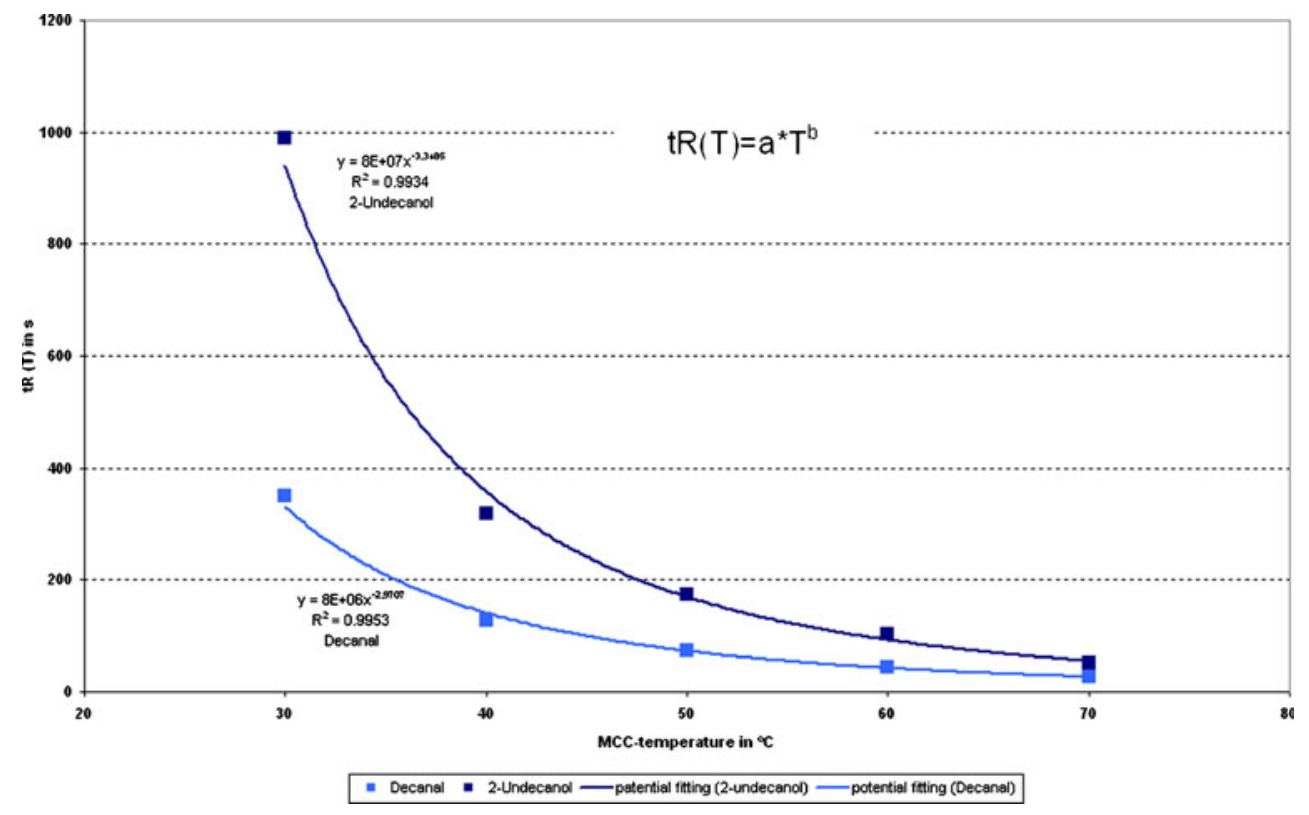

min. Therefore, the influence of small changes of the flow rate around the working point should be investigated. The influence of small deviations in carrier gas flow rate in the range from 145 to $155 \mathrm{~mL} / \mathrm{min}$ shows a linear relationship with the calculated retention time of 2-nonanone $\left(r^{2}=\right.$ 0.999). For this range of carrier gas flow rates from 145 to $155 \mathrm{~mL} / \mathrm{min}$, the difference between the linear approximation and the calculated retention times is negligible. Therefore, at least for the normal operation of the MCC at $150 \mathrm{~mL} / \mathrm{min}$ and small deviations, a linear regression alignment is a suitable approximation.

For sample introduction from the sample loop into the MCC, a six-way-valve is toggled and the carrier gas flow is redirected through the sample loop to the MCC. This toggle leads to an initial backpressure dip. After a few seconds, the pressure before the MCC again shows a steady state. This effect might explain the more unstable retention time of compounds with a retention time less than $20 \mathrm{~s}$. In this retention time range, the benefit of an alignment procedure is less than for compounds with a retention time of more than $20 \mathrm{~s}$.

Influence of column temperature

To investigate the influence of different MCC temperatures on the retention time, the MCC temperature was varied
Fig. 4 Variation of the retention time of 2-nonanone with different MCC temperatures around the normal operation temperature of $40{ }^{\circ} \mathrm{C}$. The linear regression is indicated by the solid line. Error bars mark the time range of one spectrum in the MCC-IMS chromatogram for the normal set-up

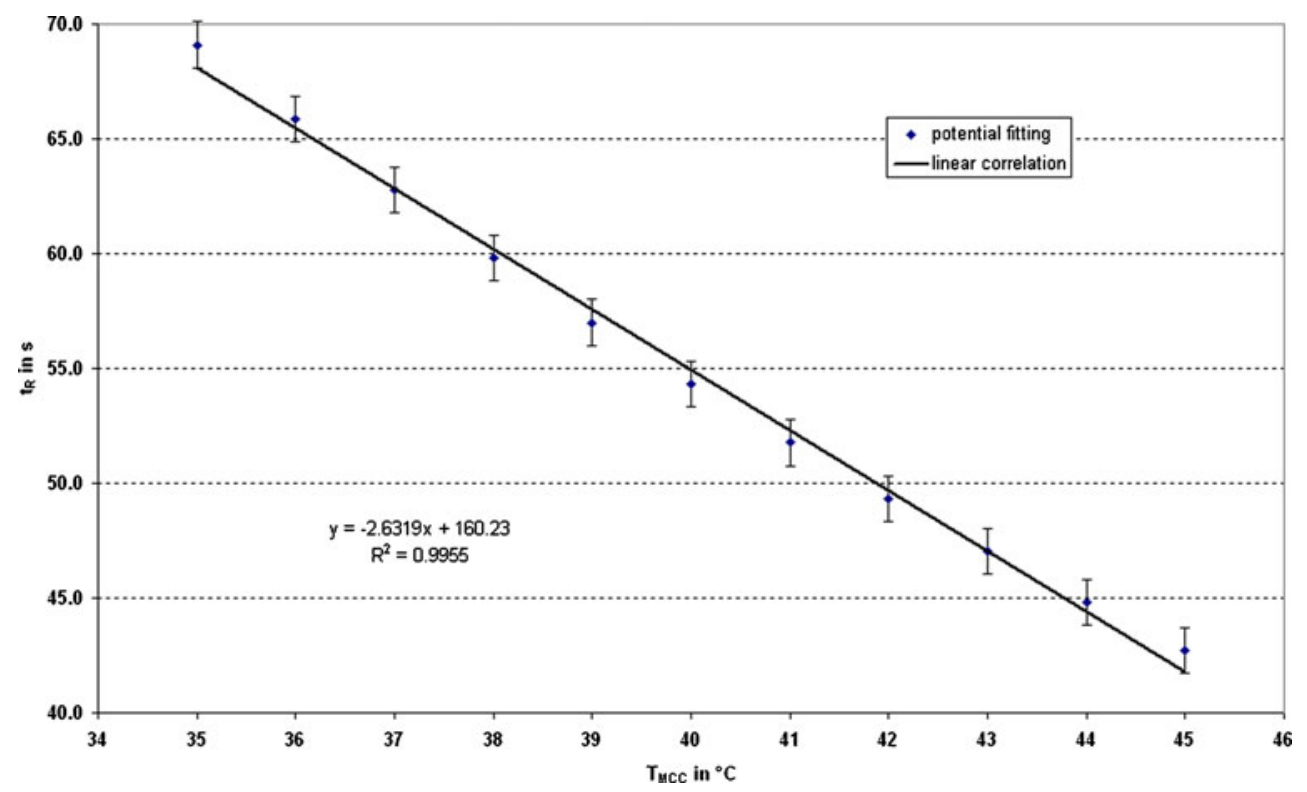


Table 2 Retention times ( \pm standard deviation ) for eight compounds measured with two different MCC ion mobility spectrometers (IMS) given as mean(s) before alignment

\begin{tabular}{|c|c|c|c|c|c|}
\hline \multirow[t]{2}{*}{ Compound } & \multicolumn{2}{|c|}{ MCC-IMS 1} & \multicolumn{2}{|c|}{ MCC-IMS 2} & \multirow{2}{*}{$\begin{array}{l}\text { Difference } \\
\text { Mean } t_{\mathrm{R} \mathrm{Ni} 03} \text {-mean } t_{\mathrm{R} \mathrm{Ni} 07}\end{array}$} \\
\hline & Replicates & $t_{\mathrm{R} \text { measured }}$ mean $(\mathrm{s})$ & Replicates & $t_{\mathrm{R} \text { measured }}$ mean $(\mathrm{s})$ & \\
\hline 2-Hexanone & 43 & $6.67 \pm 2.13$ & 19 & $5.25 \pm 0.57$ & 1.42 \\
\hline 2-Heptanone & 45 & $11.38 \pm 2.94$ & 19 & $10.04 \pm 0.47$ & 1.34 \\
\hline 2-Octanol & 45 & $22.27 \pm 5.28$ & 19 & $23.05 \pm 1.09$ & -0.78 \\
\hline D-Limonene & 34 & $24.16 \pm 6.26$ & 19 & $25.79 \pm 2.93$ & -1.63 \\
\hline 1-Octanol & 45 & $38.06 \pm 9.18$ & 19 & $43.16 \pm 1.8$ & -5.1 \\
\hline 2-Nonanone & 45 & $40.85 \pm 10$ & 19 & $45.56 \pm 1.29$ & -4.71 \\
\hline 1-Decanol & 41 & $200.25 \pm 21.24$ & 17 & $253.09 \pm 8.56$ & -52.84 \\
\hline 2-Undecanol & 23 & $252.74 \pm 40.95$ & 16 & $303.93 \pm 13.91$ & -51.19 \\
\hline
\end{tabular}

2-Nonanone was used as the alignment substance.

from 30 to $70{ }^{\circ} \mathrm{C}$ in steps of $10^{\circ} \mathrm{C}$ in the permeation tube set-up. Fifteen substances (Table 1, indexed by superscript b) that are eluted in a broad range of retention times were used for this purpose. As expected [21], the slope for each compound under a changed MCC temperature follows a specific correlation (examples for 2-undecanol and decanal in Fig. 3). However, the linear factor $a$ and the exponent $b$ for each particular analyte depend on the retention time. Hence, the influence of a broad range of column temperatures on the retention time can only be described by a general, but quite complex, potential function of the temperature with a linear factor and exponent depending on the retention time itself.

Analogous to the carrier gas flow rate, the influence of small deviations $\left( \pm 5^{\circ} \mathrm{C}\right)$ of the MCC temperature on the retention time in the range of the normal operation of $40{ }^{\circ} \mathrm{C}$ was investigated. The results are presented in Fig. 4. Comparable to small flow rate deviation around the normal operation, a linear regression is also a very good approxima- tion for small temperature variations. The error bars in Fig. 4 indicate the time deviation to record one spectrum. It can be seen that, by assuming a linear approximation instead of the complex realistic one mentioned before, the error is only in this range and is therefore acceptable.

Applicable alignment procedure

As expected, the influence of both the carrier gas flow rate and the column temperature was found to be non-linear as described already. However, only small deviations in temperature and flow rate can be expected for normal operation, excluding significant deviations due to a different experimental set-up. Technical reasons can cause unstable flow rate and temperature values in the range of less than $5 \mathrm{~mL} / \mathrm{min}$ and $5{ }^{\circ} \mathrm{C}$, respectively. Furthermore, under realistic conditions, one cannot distinguish whether a retention time deviation is caused by deviations in flow rate or in temperature and, as a consequence, which alignment

Table 3 Retention times for eight compounds measured with two different MCC-IMS given as mean(s) after alignment

\begin{tabular}{|c|c|c|c|c|c|}
\hline \multirow[t]{2}{*}{ Compound } & \multicolumn{2}{|c|}{ MCC-IMS 1} & \multicolumn{2}{|c|}{ MCC-IMS 2} & \multirow{2}{*}{$\begin{array}{l}\text { Difference } \\
\text { Mean } t_{\mathrm{R} \mathrm{Ni} 3} \text {-mean } t_{\mathrm{R} \mathrm{N} \text { N07 }}\end{array}$} \\
\hline & Replicates & $t_{\mathrm{R} \text { aligned }}$ mean $(\mathrm{s})$ & Replicates & $t_{\mathrm{R} \text { aligned }}$ mean $(\mathrm{s})$ & \\
\hline 2-Hexanone & 43 & $8.48 \pm 2.02$ & 19 & $5.91 \pm 0.63$ & 2.57 \\
\hline 2-Heptanone & 45 & $14.37 \pm 2.79$ & 19 & $11.32 \pm 0.62$ & 3.05 \\
\hline 2-Octanol & 45 & $28.01 \pm 2.24$ & 19 & $25.95 \pm 1.01$ & 2.06 \\
\hline D-Limonene & 34 & $30.43 \pm 2.4$ & 19 & $29.06 \pm 3.51$ & 1.37 \\
\hline 1-Octanol & 45 & $47.81 \pm 1.55$ & 19 & $48.6 \pm 1.45$ & -0.79 \\
\hline 2-Nonanone & 45 & $51.3 \pm 0$ & 19 & $51.3 \pm 0$ & Used for alignment \\
\hline 1-Decanol & 41 & $264.66 \pm 11.27$ & 17 & $283.99 \pm 7.82$ & -19.33 \\
\hline 2-Undecanol & 23 & $329.08 \pm 9.6$ & 16 & $341.99 \pm 10.4$ & -12.91 \\
\hline
\end{tabular}

2-Nonanone was used as the alignment substance. 
would be appropriate. Therefore, a linear alignment procedure for the retention time is an appropriate method for application to real MCC-IMS data.

The deviation of a linear correlation for the influence of carrier gas flow rate and column temperature on retention time - fixed at the working points $\left(40{ }^{\circ} \mathrm{C} / 150 \mathrm{~mL} / \mathrm{min}\right)$ from the non-linear regression was determined. It was less than $0.05 \%$ in $t_{\mathrm{R}}$ for flow deviations of $\pm 5 \mathrm{~mL} / \mathrm{min}$ and less than $1.5 \%$ in $t_{\mathrm{R}}$ for $\mathrm{a} \pm 5{ }^{\circ} \mathrm{C}$ temperature deviation. As both temperature and flow rate are electronically controlled and regularly calibrated, common temperature and flow rate deviations can be expected to be smaller than the values mentioned previously. The findings support the use of a linear correlation as a good approximation for normal operation with a total error of less than $2 \%$.
Fig. 5 Example alignment of a standard gas mixture. The ovals indicate the expected position of compounds in the topographic plot (BB_IMSAnalysis 1.0, ISAS, Dortmund, Germany) before (a) and after (b) alignment. $M$ monomer, $D$ dimer

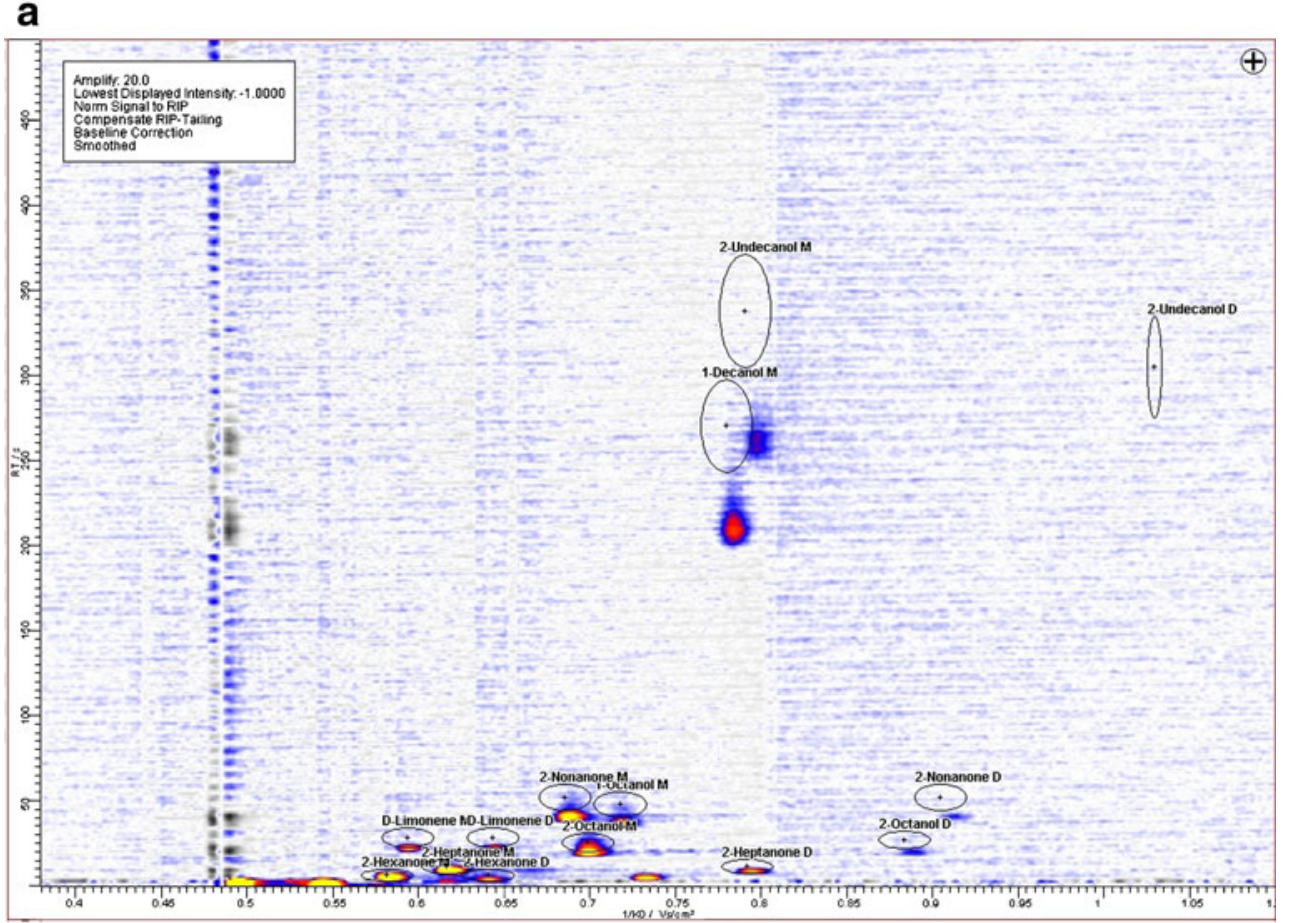

b

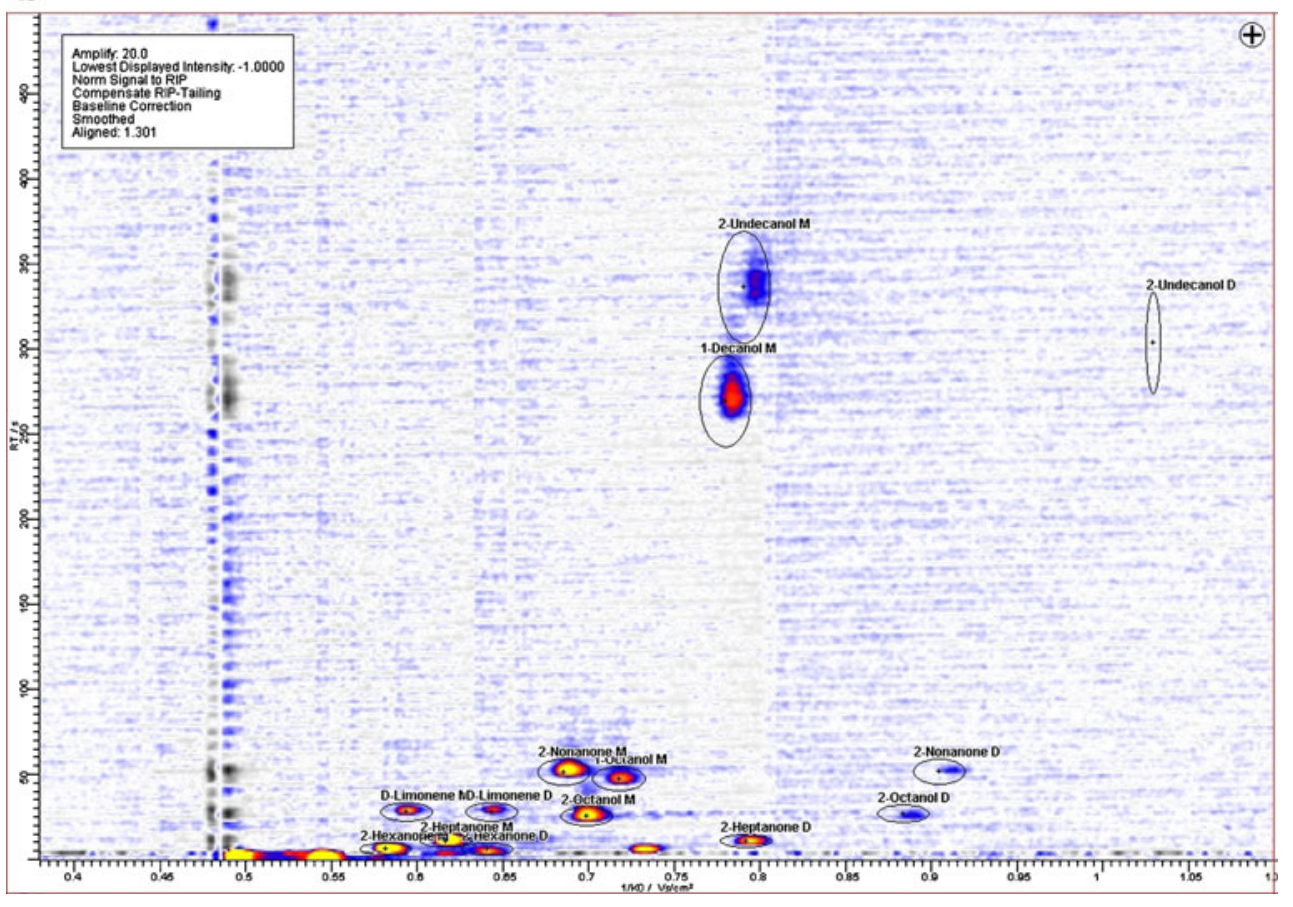


For such a linear alignment procedure, the correction of normal, technical deviations of both relevant parameters can be described as

$t_{\mathrm{R} \text { aligned }}=F_{\mathrm{MCCalig}} t_{\mathrm{R} \text { measured }}$.

The linear factor $F_{\text {MCCalign }}$ can be determined from the ratio of the standard retention time of a known analyte to the measured retention time.

\section{Alignment of reference mixtures}

For validation of the linear alignment, Eq. 4 was first applied to data generated from two different IMS obtained from the analyses of a reference mixture of eight analytes (see Tables 2 and 3 ) in the permeation tube set-up. The retention times determined before alignment using the alignment procedure described by Eq. 4 are summarised in Table 2. 2-Nonanone was used as a reference for the

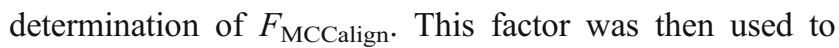
align each chromatogram. After this procedure, the retention times of the other analytes were determined again and they are summarised in Table 3. For retention times of more than $25 \mathrm{~s}$, the linear alignment leads to significant improvement of the correspondence of the positions of the signals in the data from both instruments. For shorter retention times, the mean difference between both instruments slightly increases after alignment. This effect might be due to the backpressure decline after switching the sixway-valve as mentioned previously. However, this is in the range of one recorded spectrum and therefore has no significant influence on the identification of the signals.

Figure 5 demonstrates the effect of alignment in the case of using 2-nonanone for alignment of an analysis of the 15-analyte mixture (see Table 1). The ovals indicate the expected area of the eight compounds used with monomer and some dimer signals. Figure 5a shows the raw data of the MCC-IMS analysis of the reference mixture and Fig. 5b shows the aligned data. A significant improvement of the concordance of detected signals and expected retention times is obvious. The evaluation of about 80 measurements of reference mixtures with seven different MCC-IMS showed an improvement of the aligned data over the entire retention time range (5-300 s) with regard to the standard deviation of the retention time (Table 4). The deviation of the retention time is significantly reduced over all eight substances from 22.2 to $10.0 \%$. The improvement is more obvious for the six substances with retention times of more than $20 \mathrm{~s}$ (relative standard deviation reduced from 21.2 to $5.3 \%$ ).

\section{Alignment of human breath analyses}

For a realistic application, we evaluated the alignment procedure for data obtained from human breath samples. Breath analyses were performed in a population of 33 mechanically ventilated patients in a university hospital intensive care unit (Department of Anaesthesiology, Emergency and Intensive Care Medicine, University of Göttingen, Germany). The study was started after the approval of the local ethics committee and conferred consent has been obtained. For the mechanically ventilated patients, a gas sample tube (polytetrafluorethylene, $220 \mathrm{~cm}, 1.6 \mathrm{~mm}$ S1810-26, Bohlender, Grünsfeld, Germany) was attached on the patient side of the heatmoisture exchange filter (Teleflex Medical, Humid-Vent ${ }^{\circledR}$ Filter Compact S, REF 19401, Teleflex Medica, Kernen, Germany). Gas sampling control was performed by carbon dioxide measurement. Carbon dioxide content was measured by mainstream capnography (IRMA, PhaseIn, Danderyd, Sweden). If the carbon dioxide pressure exceeded $3.33 \mathrm{kPa}$, the sample loop $(10 \mathrm{~mL})$ was flushed with the sample over a T-piece connection using a pump to obtain an end-tidal sample. A sample $(10 \mathrm{~mL})$ was obtained from multiple breaths (20-s expiratory time) and was then injected

Table 4 Retention times for eight compounds measured with seven different MCC-IMS given as mean(s) and relative standard deviation (RSD) before and after alignment

\begin{tabular}{llllll}
\hline Substance & Replicates $(n)$ & Mean $t_{\mathrm{R} \text { measured }}(\mathrm{s})$ & $t_{\mathrm{R} \text { measured }}$ RSD $(\%)$ & Mean $t_{\mathrm{R} \text { aligned }}(\mathrm{s})$ & $t_{\mathrm{R} \text { aligned }} \mathrm{RSD}(\%)$ \\
\hline 2-Hexanone & 84 & 6.23 & 27.9 & 7.26 & 2.7 \\
2-Heptanone & 86 & 11.16 & 22.4 & 27.87 & 20.4 \\
2-Octanol & 86 & 23.83 & 21.1 & 29.55 & 9.4 \\
D-Limonene & 75 & 26.2 & 21.1 & 47.73 & 9 \\
1-Octanol & 85 & 41.95 & 21.7 & 51.3 & 3.5 \\
2-Nonanone & 86 & 45.12 & 21.9 & 271.81 & Used for alignment \\
1-Decanol & 69 & 225.25 & 19.7 & 338.25 & 5.7 \\
2-Undecanol & 60 & 305.51 & 21.9 & 4.3 \\
\hline
\end{tabular}

2-Nonanone was used as the alignment substance. 
into the MCC directly. We chose a data set of 183 measurements. Benzothiazole $\left(K_{0} 1.74 ; t_{\mathrm{R} \text { aligned }} 118.3 \mathrm{~s}\right)$ was present in all data sets as a permanent contaminant of the synthetic air supply and therefore was used as the alignment substance. The effect of the alignment was validated using the signal due to a specific medicament [diisopropylphenol (propofol); $\left.K_{0} 1.48\right]$ [6], a sedative, which occurred most frequently in expired air from ventilated patients.
Figure 6 shows an example of the effect of the alignment of the chromatogram on benzothiazole for a selected case (Fig. 6a before alignment and Fig. 6b after alignment). The ovals indicate the position of benzothiazole and diisopropylphenol, thus indicating a significant improvement. The variation of the retention time of benzothiazole in all measurements was determined with a mean value of $124.5 \mathrm{~s}$ (standard deviation $8.9 \mathrm{~s}$ ), thus demonstrating the
Fig. 6 Example alignment of real breath analysis. The topographic plot (BB_IMSAnalysis 1.0, ISAS, Dortmund, Germany) is presented before (a) and after (b) alignment

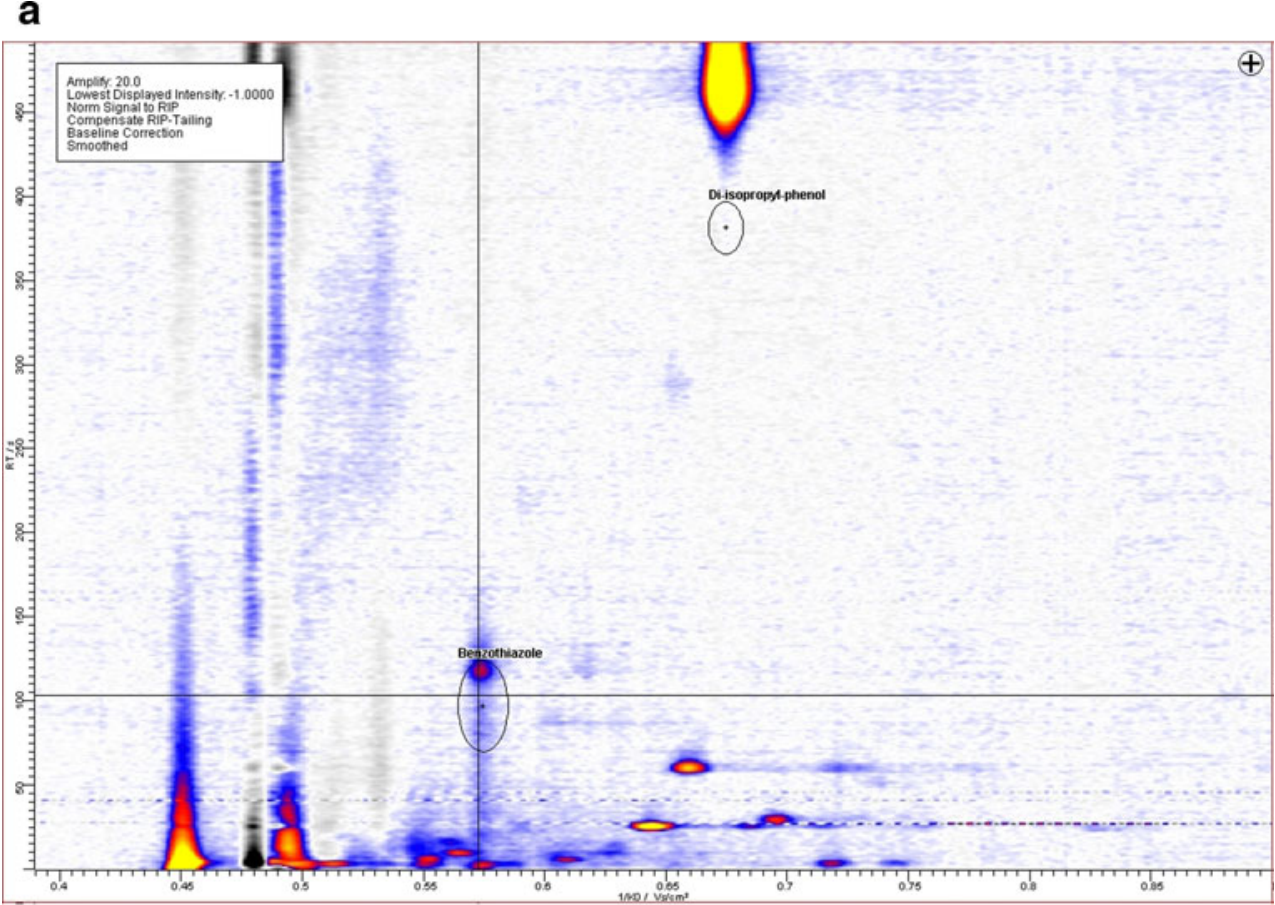

b

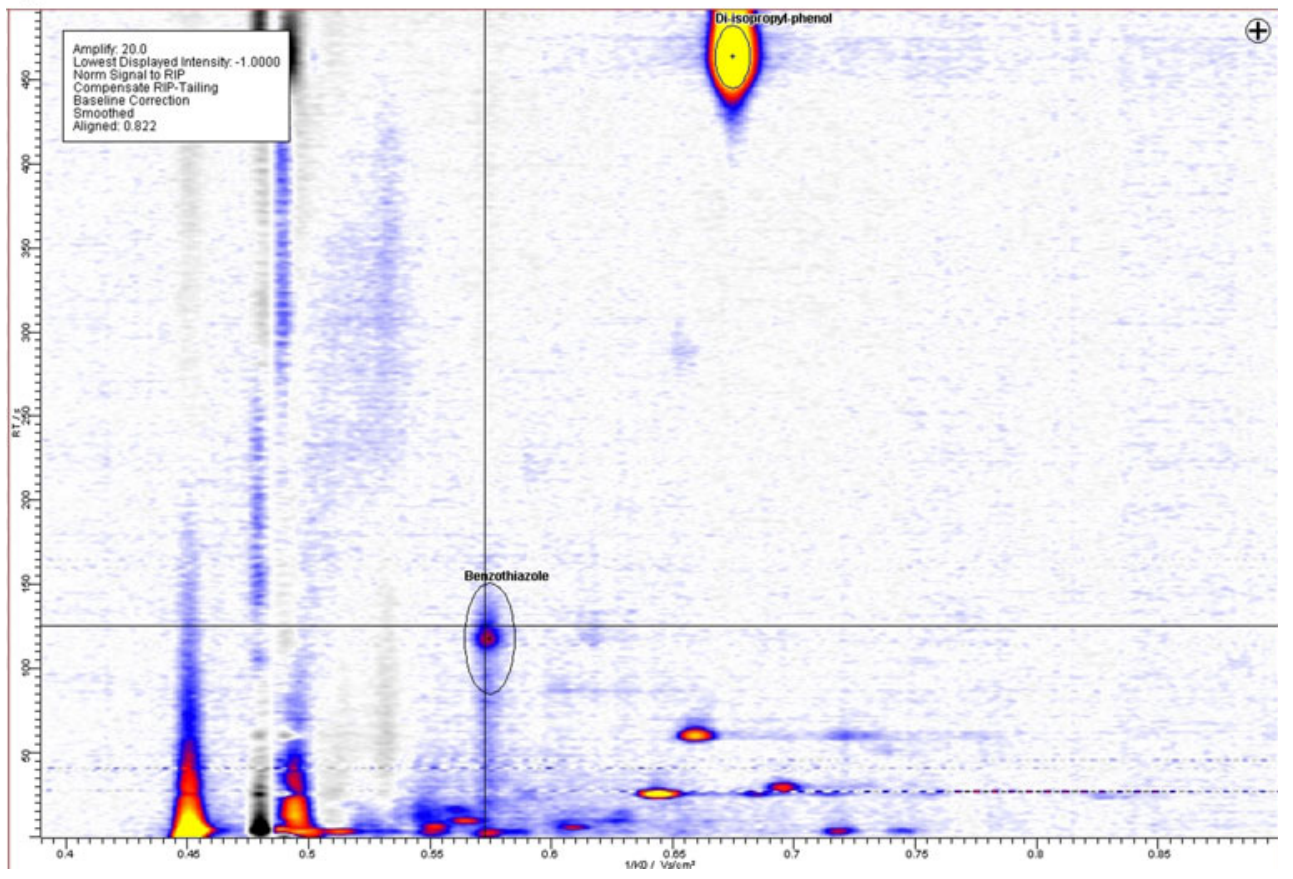


significant influence of accidental deviations in flow rate and MCC temperature on the breath analysis results. This entire data set was then aligned to the benzothiazole signal, resulting in a mean alignment factor of 0.96 (standard deviation 0.07).

The variation of the retention time of diisopropylphenol before and after alignment was shifted by alignment from $488.6 \mathrm{~s}$ (standard deviation $34.3 \mathrm{~s}$ ) to $464.4 \mathrm{~s}$, with a significantly lower standard deviation of $11.2 \mathrm{~s}$. After alignment the values followed a Gaussian distribution. This example demonstrates the suitability of the linear alignment of the retention time obtained from MCC for various compounds in real samples. Using this approach, a MCCspecific calibration is not necessary.

\section{Conclusion and outlook}

A linear alignment of the retention time leads to significantly higher accuracy of the retention time determined by the MCC-IMS and therefore enables a more precise identification of analytes in complex samples by comparison with databases, in particular of metabolites in human breath. Although the influences of both temperature and flow rate on the retention time are non-linear and, in the case of temperature, quite complex, a linear alignment is preferred as, in real applications, one cannot decide whether deviations in the retention time are due to one of the parameters or even to a combination of both.

For reference gas mixtures, the linear alignment was validated successfully. It reduces the random error caused by small, instrumental deviations in temperature and in carrier gas flow rate of the gas-chromatographic preseparation. The reason for such variations might be due to the tolerances of the equipment used for the control of those parameters, as well as to their failure or to faulty operation. However, during normal operation, in general, one cannot decide whether a deviation in the retention time is caused by a deviation of pressure, temperature or flow rate or even by combinations of them. Especially for compounds with higher retention times, the alignment is an effective procedure to achieve more precise values of the retention time. For medical applications, such as the diagnosis of different diseases, it is essential to achieve high sensitivity and specificity. As a consequence of the successful alignment procedure, the application of internal standards, as frequently requested, seems to be dispensable in most cases as some known analytes are available in most samples.

However, improvement is still required with regard to short retention times. This could be solved by technical modifications to avoid the backpressure decline after switching of the sample valve. Otherwise, a non-linear alignment procedure for this range of retention times could also solve the problem. Nevertheless, the deviations in the retention time in this scope are in the range $1-2 \mathrm{~s}$ and therefore are not critical, as $1 \mathrm{~s}$ is equivalent to a single spectrum in the normal MCC-IMS set-up used for human breath analyses.

Acknowledgements The financial support of the Bundesministerium für Bildung und Forschung and the Ministerium für Wissenschaft und Forschung des Landes Nordrhein-Westfalen is gratefully acknowledged. The dedicated work of Luzia Seifert, Susanne Krois, Jansje Schwab, Rita Fobbe and Stefanie Güssgen, all technicians at ISAS, was indispensable for the success of the investigations. The assessment of breath analyses, in particular by Eike Habakkuk Carstens, Tobias Gehrig, Lena Kristina Hofmann and Siobhán Ulbricht, was essential for the investigations.

Open Access This article is distributed under the terms of the Creative Commons Attribution Noncommercial License which permits any noncommercial use, distribution, and reproduction in any medium, provided the original author(s) and source are credited.

\section{References}

1. Baumbach JI, Eiceman GA (1999) Appl Spectrosc 53:338A-355A

2. Eiceman GA, Karpas Z (1994) Ion mobility spectrometry. CRC, Boca Raton

3. Hill HH Jr, Siems WF, St. Louis RH, McMinn DG (1990) Anal Chem 62:1201A-1209A

4. Roehl RE (1991) Appl Spectrosc Rev 26:1-57

5. Westhoff M, Litterst P, Freitag L, Baumbach JI (2007) J Physiol Pharmacol 58(Suppl 5):739-775

6. Perl T, Carstens E, Hirn A, Quintel M, Vautz W, Nolte J, Jünger M (2009) Br J Anaesth 103:822-827

7. Westhoff M, Litterst P, Freitag L, Bader S, Baumbach JI (2009) Thorax 64:744-748

8. Schmidt H, Tadjimukhamedov F, Mohrenz IV, Smith GB, Eiceman GA (2004) Anal Chem 76:5208-5217

9. Vautz W, Baumbach JI (2008) Int J Ion Mobil Spectrom 11:35-41

10. Baumbach JI (2008) Int J Ion Mobil Spectrom 11:3-11

11. Vautz W, Mauntz W, Engell S, Baumbach JI (2009) Macromol React Eng 3:85-90

12. Vautz W, Baumbach JI, Jung J (2006) J Inst Brew 112:157-164

13. Vautz W, Zimmermann D, Hartmann M, Baumbach JI, Nolte J, Jung J (2006) Food Addit Contam 23:1064-1073

14. Vautz W, Schmäh M (2009) Int J Ion Mobil Spectrom 12:139-147

15. Kanu AB, Hill HH Jr (2008) J Chromatogr A 1177:12-27

16. Vautz W, Bödecker B, Bader S, Perl T (2009) Int J Ion Mobil Spectrom 12:47-57

17. Eiceman GA, Nazarov EG, Stone JA (2003) Anal Chim Acta 493:185-194

18. Kaur-Atwal G, O'Connor G, Aksenov AA, Bocos-Bintintan V, Thomas CLP, Creaser CS (2009) Int J Ion Mobil Spectrom 12:1-14

19. Ruzsanyi V, Baumbach JI, Sielemann S, Litterst P, Westhoff M, Freitag L (2005) J Chromatogr A 1084:145-151

20. Vautz W, Sielemann S, Baumbach JI (2004) Anal Chim Acta 513:393-399

21. Lu P, Zhang X, Yang L, Xu G, Zhang Y (1994) Anal Sci 10:241-245 